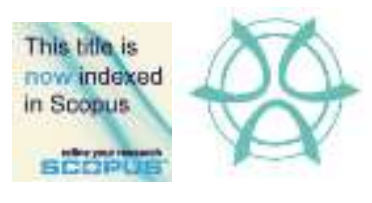

\title{
SPECTACLE OF CONSERVATION AND TOURISM IN PROTECTED AREAS: ANALYSIS OF MANAGEMENT, ISSUES AND TOURIST SATISFACTION
}

\author{
Normah Abdul Latip ${ }^{1}$, Mastura Jaafar ${ }^{2}$, Azizan Marzuki ${ }^{3}$, Kamand \\ Mohammadzadeh Roufechaei ${ }^{4}$, Mohd Umzarulazijo Umar ${ }^{5}$ \\ 1,2,3,4,5 School of Housing Building and Planning \\ UNIVERSITI SAINS MALAYSIA
}

\begin{abstract}
National parks serve as rural ecotourism attractions, even though this area is very fragile. Therefore, conservation management must be implemented to ensure the balance of the environment is maintained. This study aims to study the relationship between park management, issues and tourist satisfaction in a protected area, Kinabalu Park. Moreover, this study considers the mediating role of environmental issues on the relationship between park management and tourist satisfaction. Overall, 351 respondents agreed to participate. A questionnaire survey was administered to visitors of Malaysia's Kinabalu National Park. In total, 351 completed questionnaires were returned and have been analysed using Partial Least Squares-Structural Equation Modelling (PLS-SEM). Partial Least Squares-Structural Equation Modelling (PLS-SEM) was used to analyze the resultant data using SmartPLS 2.0. The results showed that park management has a strong effect on tourist satisfaction and environmental issues. The results also revealed that environmental issues play a mediating role in the relationship between park management and tourist satisfaction. The findings of this study make a significant contribution to our current understanding of the importance of park management, especially in the protected area as well as addressing the existing issues and provide positive satisfaction to tourists. Through the results, it will significantly contribute to the conservation and management of the protected area to be more sustainable in the future.
\end{abstract}

Keyword: Conservation and park management, environmental issues, tourist satisfaction, Kinabalu National Park

\footnotetext{
${ }^{1}$ Senior Lecturer at Universiti Sains Malaysia Email: norma_abdlatip@usm.my
} 
Normah Abdul Latip \& Mastura Jaafar, Azizan Marzuki, K.M. Roufechaei, MU Umar

Spectacle of Conservation and Tourism in Protected Areas: Analysis of Management, Issues and Tourist Satisfaction

\section{INTRODUCTION}

Tourism provides an important incentive for conserving the natural resources of national parks (Weaver, 2000). Interest in nature-based (Abdul et al., 2013) tourism has grown considerably over recent decades, making it an increasingly important sector of the tourism industry. Nature-based tourism refers to tourism in protected areas or park lands, including national park (Eagles, 2002). Countries blessed with an abundance of natural aesthetic resources create tourism value and competitiveness by capitalizing upon these natural resources. Eagles (2002) argues that national parks are "closely associated with nature-based tourism, being a symbol of a high quality natural environment with a well-designed tourist infrastructure" (p. 133). Nevertheless, the growing number of visitors to these parks is becoming a significant issue (World Tourism Organization, 1992). With ever-larger shares of land being devoted to conservation, conflicts invariably arise in response to the spatial distribution of costs and benefits, which may be considered unfair for local residents. Consequently, there is often strong public debate preceding the establishment of protected areas. This is especially significant in the case of internationally recognized national parks pursuant to the World Conservation Union's guidelines (Dudley, 2008; Thomas \& Middleton, 2008).

National parks are vital assets in the conservation of biodiversity (Fennell \& Nowaczek, 2010). As such, national parks are used to ensure the preservation of habitats and wildlife. Nevertheless, the establishment and management of national parks often invoke considerable controversy. To this end, Eagles (2014) observes that firm government action is often necessary to ensure the responsible and sustainable management of national parks. Such governmental action is necessary in response to the enormous pressure faced by park administrators and managers to supply additional tourist facilities and to offer an increased range of activities to entice new tourists (Huang, Deng, Li, \& Zhong, 2008). As such, national parks must now balance the conflict between economic growth and tourism, and the need to promote conservation efforts aimed at protecting the very natural resources tourists come to enjoy.

Tourism is a significant contributor to the Malaysian economy, and the Malaysian government is committed to supporting the growth of the tourism industry. However, the rapid growth of the Malaysian tourism sector has come at the cost of the increased use of the nation's natural resources. Consequently, tourism resources, such as Kinabalu Park, are often adversely impacted through the over-use and exploitation of tourism destinations. Blanke and Chiesa (2013) observe that Malaysia has struggled to cope with the rising demand on its environmental resources, with Malaysia's environmental sustainability rating having dropped from 44 to 61 in 2008 according to the T\&TC report. Moreover, Malaysia's ranking on $\mathrm{CO}_{2}$ emissions has dropped from 86 in 2008 to 103 in 2013 (Blanke \& Chiesa, 2013). According to Shahbaz et al., (2015), the rapid 
emergence of environmental consequences and climate change have created additional costs for the country's development objectives.

Kinabalu Park was gazetted in 1964 and it is well-known for its biodiversity (Tay et al., 2016). Kinabalu is one of the oldest world heritage sites in Malaysia, after been recognized by UNESCO in 2013. The park's management, Sabah Parks, aims to promote Kinabalu Park as a nature tourism hotspot while simultaneously ensuring that the park meets world standards for sustainability and conservation. Kinabalu Park is considered a strategic environmental asset because of its high levels of biodiversity, thus making its conservation an imperative (Tay et al., 2016).

Nevertheless, the increase in the number of tourists has had an adverse impact on Kinabalu Park (Latip, et al., 2015). According to Weaver (2000), there is a certain inevitability with respect to the deleterious effects of human activities on habitat areas. For environmentally sensitive areas, such as Kinabalu Park, the relationship between tourism and environmental sustainability has become an increasingly important subject of interest (Jaafar, Kayat, Tangit, \& Yacob, 2013). Moreover, given the suggestion of Buckley, Robinson, Carmody, and King (2008), that the effectiveness of protected area management is rarely monitored, this relationship between tourism and environmental sustainability becomes increasingly salient.

Increasing the number of visitors to a nature-based destination puts increased pressure on local ecosystems, thus highlighting the importance of effective park management in ensuring the sustainability of development and preservation programs (Bulatovic \& Tripkovic-Markovic, 2015; Gilmore \& Simmons, 2007). According to Parks Enactment 1984, Sabah Parks is responsible for protecting and improving nature reserves throughout Sabah, including Kinabalu Park. Moreover, the Act mandates that Sabah Parks will coordinate and conduct systematic planning and action pursuant to these conservation and improvement goals. Tayet et al. (2016), however, observes that agencies responsible for balancing environmental preservation and tourism promotion have a tendency to neglect environmental issues in favor of the economic benefits of tourism. For hotspots areas like Kinabalu Park, any strategic management plan focused on environmental conservation must also take into consideration the need to ensure tourist satisfaction. Tubb (2003) would suggest that this is a reasonable approach to park management given that conservation should emphasize environmental issues.

Several studies suggest that tourist satisfaction is a good predictor of intentions to revisit a destination and to recommend the destination to other people (Correia, Kozak, \& Ferradeira, 2013; Lee, 2015; Sangpikul, 2018). Therefore, environmental issues such as air, noise, and water pollution are important to revisit because these issues inform subsequent tourist recommendations. Consequently, having appropriate management systems in 
Normah Abdul Latip \& Mastura Jaafar, Azizan Marzuki, K.M. Roufechaei, MU Umar

Spectacle of Conservation and Tourism in Protected Areas: Analysis of Management, Issues and Tourist Satisfaction

place in Kinabalu National Park can help to ensure the sustainability of tourism development while promoting tourism satisfaction. To this end, we argue the importance of investigating best practices in the management of Kinabalu Park, environmental conservation, and tourist satisfaction. This investigation has implications for existing park management policies and practices (Rasoolimanesh, Dahalan, \& Jaafar, 2016).

The aims of this study are to determine: (a) the relationship between park management, tourist satisfaction, and environmental issues; and (b) the mediating role of environmental issues between park management and tourist satisfaction from the perspective of visitors to Kinabalu National Park. The findings of this study can benefit the management of Kinabalu National Park, facilitating the planning and management activities of key stakeholders. In addition, research focused on park management can be used to inform environment conservation efforts, thus improving the quality of the tourist experience and the satisfaction of visitors to the park. The findings of this paper also highlight the essential role of park management in future tourism development. Having reviewed the park management, environmental and tourist satisfaction literature, this paper goes on to describe the research methodology, results and undertakes to explore the implications of these findings in relation to the relevant literature.

\section{RESEARCH BACKGROUND}

\section{Tourism development and environmental issues}

Tourism is one of the largest developing industries in the global economy, having substantial environmental, social, cultural, and economic impacts. Nevertheless, tourism development is often a double-edged sword, creating both positive (e.g., job creation and image enhancement), and negative impacts on the biophysical (e.g., water and air pollution, ecosystem degradation), and social/cultural environment (e.g., loss of culture traditions) if not well planned, developed or managed (Azam et al., 2018). Without appropriate management, tourism development can have a number of potentially harmful effects on a destination's ecosystem and environment. Rabbany et al., (2013) argue that dysfunctional or poorly managed tourism development inevitably results in the unbalanced use of natural resources, resulting in significant environmental harm.

The growth of ecotourism parallels rising concerns about environmental issues in protected areas (Benedetto et al., 2016; Xu \& Fox, 2014; Latip et al., 2018). While previous investigations of ecotourism development and environmental issues in protected areas have found considerable variation in the environmental perceptions of visitors, it remains unclear whether and how these visitor environmental perceptions might affect their support for ecotourism development. Instead, research interests have tended to focus on the value or benefits of ecotourism development as a source of revenue for national parks or 
PLANNING MALAYSIA

Journal of the Malaysia Institute of Planners (2020

as a driver for improved conservation efforts (Landorf, 2009). To this end, the tourism industry has the potential to benefit ecosystems by engendering a renewed focus on environmental protection and conservation programs. To some extent, the rise in both the variety and number of protected regions and national park development projects across the world is a reflection of this renewed focus. Therefore, effective park management and planning are essential for ensuring the success of efforts to safeguard these protected areas for both the conservation of the environment itself and for leisure/tourism purposes (Jenkins \& Pigram, 2003).

Tourism-steered economic growth and development is achieved at the cost of increased pollution and environmental degradation. In the absence of any concerted efforts to promote viable and environmentally sustainable global tourism practices, it is inevitable that the effects of pollution and environmental degradation will overshadow whatever benefits might result from tourism development. Previous studies have revealed that there is a substantial correlation between environment effects and tourism development (Azam et al., 2018; Rabbany et al., 2013). Robaina-Alves, Moutinho, and Costa (2016) assert that the environmental effects of tourism are particularly deleterious where there is a dependency on energy and carbon intense tourism activities and infrastructure. Few studies, however, explore the issue of tourism development and environmental pollution in the context of Malaysia. Environmental problems, such as noise, air and water pollution, and the loss of biodiversity often occur concomitant with the rapid development of tourism (Andrea, Tampakis, Tsantopoulos, \& Manolas, 2014). In fact, Rabbany et al. (2013) observes that tourism impacts every aspect of the natural and human environment, including air, water, land, built facilities, landscapes, colors, sounds, and other environmental factors. The waterscape is an important environmental element for a tourism destination. Sewage, feces, garbage, and other sources of pollution associated with tourism activities can lead to the eutrophication of water sources, spreading infectious diseases, and degrading the sources of water used to keep forests hydrated (Andrea et al., 2014; Rabbany et al., 2013). Rabbany et al. (2013) found that water pollution in many tourism areas was ultimately caused by sewage being discharged directly into sources of ground and surface water.

Moreover, the atmospheric environment in some tourism areas has been negatively impacted by the use of coal and other fuels, as well as tourist activities. Rabbany et al. (2013) reported that the air quality in many tourism area had been greatly affected due to the emission of smoke, sulfur dioxide, nitrogen oxides, and other harmful gases from the use of coal power plants and other sources of emission. An inappropriate tourism development model can result in soil erosion and desertification. Ignoring environmental protections often results in nutrients being leached out the soil, potentially leading to salinization and acidification (Andrea et al., 2014). The soundscape is another important component of the tourism environment, helping to create a comfortable environment and making a 
Normah Abdul Latip \& Mastura Jaafar, Azizan Marzuki, K.M. Roufechaei, MU Umar

Spectacle of Conservation and Tourism in Protected Areas: Analysis of Management, Issues and Tourist Satisfaction

positive contribution to the tourism experience. Nevertheless, tourism activities often cause noise pollution. Empirical research has shown that tourism activities cause considerable noise, thus having a negative impact on the local environment. Sources of noise pollution range from vehicles or machinery to tourists themselves (Azam et al., 2018).

Given the scale of negative impacts related to tourism development on the environment, a number of researchers have called for greater attention to be paid to the protection and management of tourism resources (Azam et al., 2018). A number of scholarly investigations of park management policies and practices have emerged over the last 15 years to become an essential subfield within protected area management (Eagles, 2014; Johnston \& Tyrrell, 2007; Lillestol, Timothy, \& Goodman, 2015). In part, these investigations have been motivated by a need to inform park management and government policies about growth opportunities for the redevelopment of national parks (Henderson and Fry, 2011). Park management

Effective park management is critically important for achieving desirable environmental outcomes and for the long-term viability of the ecotourism industry. Bennett and Dearden (2014) argue that many national parks exist purely on paper, serving no real purpose other than to protect them from the extractive industries. Effective park management, however, is fundamentally about ensuring that the resources of a national park are used productively, in both quantitative and qualitative terms (Getzner, Vik, Brendehaug, \& Lane, 2014). Managing natural resources is largely about managing how humans interact with the natural environment and responding to broader changes in the human and natural environment. The effectiveness of this management is influenced by the availability of resources, legislative and public support, levels of cross-scale coordination and cooperation, and a number of other rules and regulations. According to Bennett and Dearden (2014), effective park management strategies include: (a) implementing a policy of carrying capacity and establishing standards for development, (b) establishing conflict resolution strategies and zoning for multiple uses, (c) increasing knowledge and awareness through education and communication campaigns, (d) undertaking a broad approach to the management of tourist activities, and (e) the enforcement of rules and regulations.

Tourism management in protected regions, such as national parks, requires an advanced and innovative management strategy. Management strategies in natural areas should focus on tourism; as such, there is a need to consider both the promotion of ecotourism development as well as how these developments will impact local ecosystems (Tubb, 2003). To this end, effective management strategies tend to prioritize environmental issues, with the development of ecotourism a by-product of this focus (Bulatovic \& TripkovicMarkovic, 2015). However, according to Ferreira and Harmse (2014), park management retains the option to control the degree and amount of interaction 
between social and environmental interests. For example, access to natural areas can be controlled or limited through zoning, restrictions on permissible activities, as well as by educating visitors about appropriate park use (Inglis, Pearlman, \& Whitelaw, 2005). Well planned and properly managed natural areas tend to show minimal environmental impact with high sustainable economic returns and greater visitor satisfaction (Benedetto et al., 2016). Connell, Page, and Bentley (2009) observe that there is a relationship between tourism and the ecosystem, with each being dependent upon the other. Moreover, Eagles (2014) suggests that management guidelines and strategies need to be established for new tourism developments to facilitate the preservation of a protected area's cultural and natural value.

Tourism activities have a number of often unidentified negative impacts on ecosystems. Consequently, the management and planning of such activities in the context of national parks should be both tactical and ongoing (Qian, Sasaki, Shivakoti, \& Zhang, 2016). Management activities should involve all key stakeholders, the absence of which can result in knowledge gaps regarding the unique environmental values of a natural area. The absence of appropriate information can affect the decision-making efforts of authorities (Benedetto et al., 2016). Therefore, understanding tourist satisfaction is essential for the success of any tourism destination (Eagles, 2014). Destination management organizations are primarily concerned with promoting tourist satisfaction. Tourist satisfaction is important because it directly affects the economic returns enjoyed by a destination or host country. Tourist satisfaction influences visitors' selection of a destination, their consumption of products and services, as well as their decision to return to a destination. A number studies have shown that satisfied tourists tend to tell others about their positive or good experiences and plan return trips (Correia et al., 2013; Sangpikul, 2018). Tourist satisfaction is a desired psychological state that follows after direct exposure to a tourism experience or opportunity, and as such, represents a post-purchase evaluative judgment (Baker and Crompton, 2000). In a case study of Parks Canada, Banyai (2012) concludes that: "Overall experience satisfaction in a national park is highly dependent on visitors' satisfaction with the site-specific elements" (p. 115). Therefore, the investigation of tourist satisfaction is essential for ensuring sustainable park tourism management.

\section{RESEARCH METHODOLOGY}

The study data comprises of a mix of literature review, existing research reports and a questionnaire survey. This study analyses and evaluates the mediating role of environmental issues between park management and tourist satisfaction. The model for this study is illustrated in Figure 1. A number of studies highlight the influence of park management on tourism development and economic development (Bulatovic \& Tripkovic-Markovic, 2015; Eagles, 2014; Qian et al., 
Normah Abdul Latip \& Mastura Jaafar, Azizan Marzuki, K.M. Roufechaei, MU Umar

Spectacle of Conservation and Tourism in Protected Areas: Analysis of Management, Issues and Tourist Satisfaction

2016). Some studies go on to suggest that environmental issues play an important role in the revisit intentions and destination recommendations of tourists (Lee, 2015; Yousuf \& Ali, 2018). Similarly, some studies have explored the role of rules and regulations in protected areas on tourist satisfaction (Bajs, 2015; Rasoolimanesh et al., 2016). Relying on prior studies (Bulatovic \& TripkovicMarkovic, 2015; Gilmore \& Simmons, 2007), the current research assessed the relationship between park management at Kinabalu National Park, environmental issues, as well as tourist satisfaction. Therefore, the research hypotheses derived from this relationship are:

H1: Park management influences tourist satisfaction in Kinabalu National Park.

H2: Park management influences environmental issues in Kinabalu National Park.

H3: Environmental issues influence tourist satisfaction in Kinabalu National Park.

H4: Environmental issues mediate the relationship between park management and tourist satisfaction in Kinabalu National Park.

Figure 1 presents the hypothesized research model.

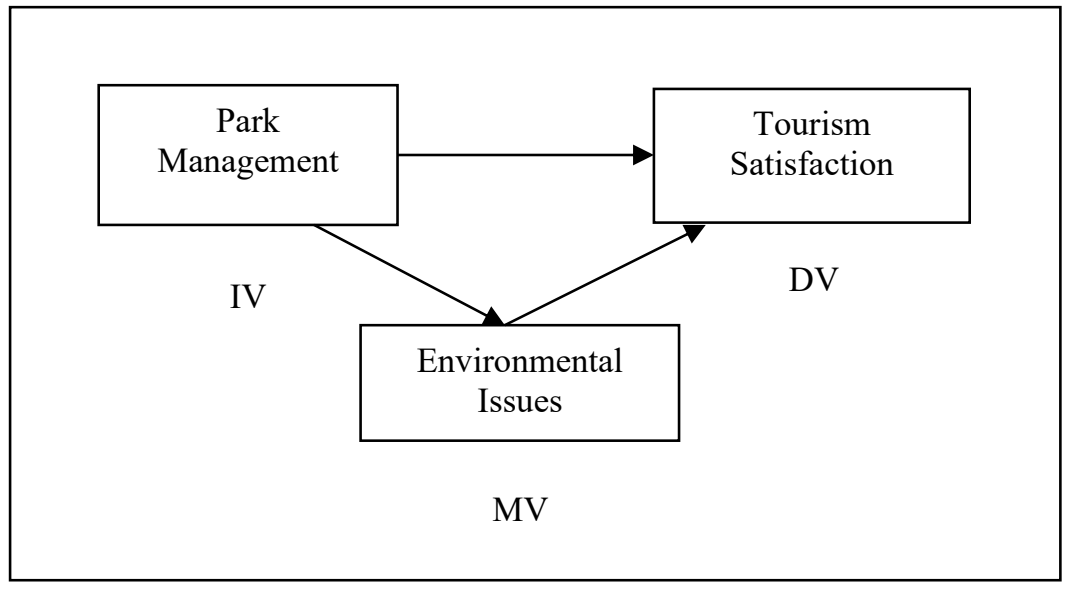

Figure 1. Proposed research model

This quantitative study assesses the hypothesized relationship and possible mediating effects of environmental issues between park management and tourist satisfaction within Kinabalu National Park. The method of data collection, which involved the use of a questionnaire survey, was influenced by preceding studies (Jimura, 2011; Nicholas, Thapa, \& Ko, 2009), and sought to examine park management, environmental issues, and tourist satisfaction. 
PLANNING MALAYSIA

Journal of the Malaysia Institute of Planners (2020

Kinabalu National Park is divided between four stations: Sayap in the Kota Belud District, Nalapak and Serinsim in the Kota Marudu District, and Monggis in the Ranau District. Respondents to this study include a sample of visitors to these areas. The questionnaire was distributed among these visitors, with 482 questionnaires having been returned. Nevertheless, only 351 questionnaires were completed or deemed usable. Consequently, the final sample includes 193 male $(55 \%)$ and 158 female (45\%) respondents. Approximately $39 \%$ of the respondents were ethnic Malays, $41 \%$ were Chinese, $16 \%$ were Indians, and $4.5 \%$ were other ethnicities. Among the respondents, 253 were aged 18-34 years, and 98 were aged 35 years or over. The majority of respondents $(82.3 \%)$ were either undergraduates or held graduate degrees.

The questionnaire was divided into four parts: respondent demographic data (4 items), park management ( 7 items), environmental issues ( 7 items), and tourist satisfaction (6 items). Respondents were asked to indicate the degree to which they agreed with each item on a Likert scale ranging 1 (strongly disagree) to 5 (strongly agree). The questionnaire also provided closed questions with respect to the respondent's background, such as gender, age, nationality, and education.

Structural Equation Modelling (SEM) was employed to analyze the relationships between the variables. SEM is an in-depth statistical method that simultaneously enables the assessment of a conceptual model. SEM enables all of the paths in a model to be examined simultaneously (Tabachnick \& Fidell, 2007). Partial Least Squares SEM (i.e., PLS-SEM) was utilized in this research because PLS allows for theory testing. PLS-SEM was conducted on the results of data collection using SmartPLS 2.0 software (Hair, Ringle, \& Sarstedt, 2011). According to previous studies, PLS-SEM requires a minimum threshold of at least 100 samples (Reinartz, Haenlein, \& Henseler, 2009); in this study, we used data derived from 351 completed questionnaires, thus exceeding this minimum threshold. Furthermore, Hair et al. (2011) suppose a ten times rule for determining sufficient sample size for PLS-SEM analysis. Based on this rule, the minimum sample size needs to be 10 times the highest number of paths designated to a specific construct. Therefore, having data derived from a sample of 351 completed questionnaires met the minimum sample size needed for this study.

\section{DATA ANALYSIS}

The questionnaire was distributed among these visitors, with 482 questionnaires having been returned. Nevertheless, only 351 questionnaires were completed or deemed usable. Consequently, the final sample includes 193 male (55\%) and 158 female (45\%) respondents. Approximately $39 \%$ of the respondents were ethnic Malays, $41 \%$ were Chinese, $16 \%$ were Indians, and $4.5 \%$ were other ethnicities. Among the respondents, 253 were aged $18-34$ years, and 98 were aged 35 years 
Normah Abdul Latip \& Mastura Jaafar, Azizan Marzuki, K.M. Roufechaei, MU Umar

Spectacle of Conservation and Tourism in Protected Areas: Analysis of Management, Issues and Tourist Satisfaction

or over. The majority of respondents $(82.3 \%)$ were either undergraduates or held graduate degrees.

Table 1: Characteristics of respondents

\begin{tabular}{cccc}
\hline \multirow{2}{*}{ Gender } & Item & $\mathbf{N}=\mathbf{3 5 1}$ & $\mathbf{( \% )}$ \\
& Male & 193 & 55 \\
\multirow{3}{*}{ Fge } & Female & 158 & 45 \\
& $18-24$ & 133 & 37.9 \\
& $25-34$ & 120 & 34.2 \\
& $35-44$ & 61 & 17.4 \\
& $45-54$ & 27 & 7.7 \\
\multirow{3}{*}{ Ethnic } & $55-64$ & 10 & 2.8 \\
& & & \\
& Malays & 137 & 39 \\
& Chinese & 144 & 41 \\
& Indian & 56 & 16 \\
& Others & 14 & 4
\end{tabular}

For further analysis, the model was evaluated using a two-step PLSSEM method. Using this approach, the analysis began with the measurement model, after which the analysis moved on to the structural model (Chin, 2010; Hair et al., 2011). The validity and reliability of the relationships between the latent variables (LV) and any associated observable variables were examined during the course of analyzing the measurement model. During the structural model assessment, the relationship between the constructs themselves was subject to examination (Chin, 2010; Hair et al., 2011).

The analysis of model includes three reflective constructs: park management, environmental issues, and tourist satisfaction. Reflective constructs are so called because the measurement items for the constructs are strongly correlated with each other. Key to analyzing the measurement model is composite reliability (CR) and average variance extracted (AVE) (Chin, 2010; Hair et al., 2011). In addition, the reflective measurement model can be assessed by way of two forms of reliability: indicator reliability and construct reliability. The loadings of all indicators on their associated latent constructs were tested to distinguish indicator reliability. A loading more than 0.7 reveals adequate indicator reliability (Götz, Liehr-Gobbers, \& Krafft, 2010; Hair et al., 2011).

Table 2: Result of measurement model assessment

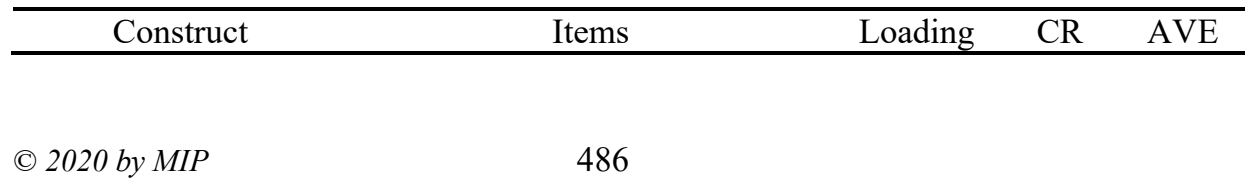


PLANNING MALAYSIA

Journal of the Malaysia Institute of Planners (2020

\begin{tabular}{|c|c|c|c|c|}
\hline \multirow[t]{8}{*}{ Park management } & & & 0.938 & 0.683 \\
\hline & $\begin{array}{l}\text { Implementing a carrying } \\
\text { capacity }\end{array}$ & 0.826 & & \\
\hline & $\begin{array}{l}\text { Establishing standards for } \\
\text { development }\end{array}$ & 0.797 & & \\
\hline & Conflict resolution strategies & 0.795 & & \\
\hline & $\begin{array}{l}\text { Increasing knowledge and } \\
\text { awareness }\end{array}$ & 0.844 & & \\
\hline & $\begin{array}{l}\text { Management of tourist } \\
\text { activities }\end{array}$ & 0.826 & & \\
\hline & Enforcing rules and regulations & 0.835 & & \\
\hline & $\begin{array}{l}\text { Establishing zoning for multiple } \\
\text { uses }\end{array}$ & 0.826 & & \\
\hline \multirow[t]{8}{*}{ Environmental issues } & & & 0.852 & 0.667 \\
\hline & $\begin{array}{l}\text { Noise pollution (vehicles, } \\
\text { visitors) }\end{array}$ & 0.712 & & \\
\hline & Air pollution (vehicles, smoke) & 0.736 & & \\
\hline & Soil erosion & 0.819 & & \\
\hline & Garbage accumulation & 0.728 & & \\
\hline & $\begin{array}{l}\text { Bad smell (garbage, toilet and } \\
\text { drainage) }\end{array}$ & 0.751 & & \\
\hline & Cleanliness of water & 0.873 & & \\
\hline & Water turbidity & 0.790 & & \\
\hline \multirow[t]{7}{*}{ Satisfaction } & & & 0.807 & 0.693 \\
\hline & $\begin{array}{l}\text { I feel I benefited from coming } \\
\text { here }\end{array}$ & 0.764 & & \\
\hline & I found the visit worthwhile & 0.703 & & \\
\hline & $\begin{array}{l}\text { The visit was as good as I had } \\
\text { hoped }\end{array}$ & 0.802 & & \\
\hline & $\begin{array}{l}\text { I would recommend this place } \\
\text { or tour to a friend }\end{array}$ & 0.793 & & \\
\hline & $\begin{array}{l}\text { If I had the opportunity, I would } \\
\text { like to come back here again }\end{array}$ & 0.864 & & \\
\hline & $\begin{array}{l}\text { Overall, I was satisfied with the } \\
\text { visit }\end{array}$ & 0.835 & & \\
\hline
\end{tabular}

Table 2 shows that all indicators had a loading greater than 0.7 . Two coefficients are typically considered to assess construct reliability: CR and, the more common coefficient, Cronbach's alpha (Chin, 2010; Götz et al., 2010). CR is the more suitable coefficient for PLS-SEM and should be greater than 0.7 (Hair et al., 2011). Table 2 indicates that the CR for both latent variables (LVs) in the measurement model was greater than 0.807 . Therefore, the results demonstrate that our measurement model had internal consistency and was reliable. The validity of the reflective measurement model also accounts for convergent and 
Normah Abdul Latip \& Mastura Jaafar, Azizan Marzuki, K.M. Roufechaei, MU Umar

Spectacle of Conservation and Tourism in Protected Areas: Analysis of Management, Issues and Tourist Satisfaction

discriminant validity (Götz et al., 2010; Hair et al., 2011). For convergent validity, LVs with an AVE greater than 0.5 were considered acceptable (Chin, 2010; Hair et al., 2011). AVE is used to measure the amount of variance in an LV as contributed by its indicators (Chin, 2010). Table 2 shows that the AVE values for all constructs used in the measurement model were higher than 0.667 and had loadings higher than 0.7 . Therefore, the convergent validity of the measurement model was more than acceptable. Discriminant validity describes the extent to which each construct is distinct from one another (Chin, 2010). Two measures must be checked to test discriminant validity: the AVE of each construct should be higher than the highest squared correlation of the construct with any other LV in the model, and the loading of an indicator with its associated LV must be higher than its loading with other LVs (Chin, 2010; Hair et al., 2011).

Table 3 shows the evaluation of the AVE of both constructs with the squared correlation of the other constructs. Table 2 reveals that the AVE of each construct is greater than the largest squared correlation of the same construct with other constructs in the model. Furthermore, the factor loadings for all items on their associated constructs was more than the cross-loading with other constructs. Consequently, the results indicate the acceptability of the reliability, convergent validity, and discriminant validity of the measurement model.

Table 3: Discriminant validity

\begin{tabular}{lccc}
\hline Constructs & Park management & $\begin{array}{l}\text { Environmental } \\
\text { issues }\end{array}$ & $\begin{array}{l}\text { Tourist } \\
\text { satisfaction }\end{array}$ \\
\hline $\begin{array}{l}\text { Park management } \\
\text { Environmental }\end{array}$ & $\mathbf{0 . 6 6 7}$ & $\mathbf{0 . 6 8 3}$ & \\
$\begin{array}{l}\text { issues } \\
\text { Tourist satisfaction }\end{array}$ & 0.205 & 0.465 & $\mathbf{0 . 6 9 3}$ \\
\hline
\end{tabular}

The R-square $\left(\mathrm{R}^{2}\right)$ measure of the endogenous constructs and the path coefficients was evaluated as part of an initial examination of the structural model (i.e., inner model) and theoretical framework (Chin, 2010; Hair et al., 2011). Chin (2010) recommends that measures of $0.67,0.33$, and 0.19 for $\mathrm{R}^{2}$ should be thought of as respectively significant, average, and weak. The path coefficients should be substantial, and the value of $\mathrm{R}^{2}$ is contingent upon the field of study. The $\mathrm{R}^{2}$ level for the environmental issues construct in the model was 0.121 , and 0.586 for the tourist satisfaction construct. The results for the structural model assessment based on the relationship between the constructs is presented in Table 4 and Figure 2. The structural model assessment, utilizing the bootstrap process with 200, 500, and 1000 re-samplings, as well as the magnitude and significance 
PLANNING MALAYSIA

Journal of the Malaysia Institute of Planners (2020

of the structural paths are consistent. Bootstrapping resulted in 1000 samples being generated from 351 cases. As indicated by Henseler, Ringle, and Sinkovics (2009), the bootstrapping method produces standard errors and t-statistics used to assess the statistical significance of the path coefficients. At the same time, the calculation of the bootstrapping confidence intervals of standardized regression coefficients forms part of the analysis. To this end, Table 4 shows the positive, strong, and substantial effect of park management on environmental issues. Park management has a substantial effect on tourist satisfaction. The results indicate a positive and significant effect of environmental issues on tourist satisfaction. Therefore, all direct effects shown in Figure 3 are significant.

Table 4: The result of assessment of structural model

\begin{tabular}{llcccc}
\hline Hypotheseses & Std.Beta & SE & t-value & Supported \\
\hline H1 Park management & $\rightarrow 0.266$ & 0.072 & 2.460 & Yes \\
$\begin{array}{l}\text { Environmental issues } \\
\text { H2 Park management }\end{array}$ & $\rightarrow 0.699$ & 0.081 & 7.596 & Yes \\
$\begin{array}{l}\text { Tourist satisfaction } \\
\text { H3 Environmental issues }\end{array}$ & $\rightarrow 0.282$ & 0.056 & 2.554 & Yes \\
Tourist satisfaction & & & & \\
\hline
\end{tabular}

Tests on the mediation hypotheses (H4) use the analytical approach described by Preacher and Hayes (2008). Using this approach, we can analyze the direct effect of park management on tourist satisfaction by removing the environmental issues construct. Figure 4 shows the results of testing these direct effects. The application of bootstrapping (1000 re-samples) allows for testing of the mediation hypotheses (Preacher \& Hayes, 2008). In addition, Sobel (1982) describes a general procedure whereby more complicated indirect effects may be tested. The Sobel test is conducted by comparing the strength of the indirect effect of $\mathrm{X}$ on $\mathrm{Y}$ to the point null hypothesis, which equals zero (Preacher \& Hayes, 2008). The determination of significant indirect effects between two variables is decided based on the $Z$ value. The null hypothesis (there is no indirect effect between two variables) is denied whenever the $Z$ value is higher than 1.96 (Hair et al., 2011).

Equation 1 is applied to identify the statistical significance of the mediation reduction. 
Normah Abdul Latip \& Mastura Jaafar, Azizan Marzuki, K.M. Roufechaei, MU Umar

Spectacle of Conservation and Tourism in Protected Areas: Analysis of Management, Issues and Tourist Satisfaction

\begin{tabular}{|l|l|l|}
\hline$=\frac{a b}{\sqrt{a^{2} s_{b}^{2}+b^{2} s_{a}^{2}}}$ & {$[1]$} \\
\hline
\end{tabular}

a: path coefficient value from IV to MV

b: path coefficient value from MV to DV

$s_{a}$ and $s_{b}$ : standard error values for the path coefficients

The $\mathrm{Z}$ value for this research model is shown in Equation 2:

$$
z=\frac{0.266 \times 0.282}{\sqrt{0.070 \times 0.003+0.079 \times 0.005}}=3.4
$$

The results in Table 5 show that park management has a significant effect on tourist satisfaction without a mediator. By adding the mediator, the effect of park management is reduced, although it continues to exert a substantial direct effect on tourist satisfaction. The $\mathrm{Z}$ value is greater than 1.96 , which means that the indirect effect of park management on tourist satisfaction in the research model is significant. Consequently, environmental issues partially mediate the relationship between park management and tourist satisfaction.

Table 5: The result of mediating effect tests

\begin{tabular}{|c|c|c|c|c|}
\hline Hypotheses & Std.Beta & SE & $\begin{array}{c}\text { Type of } \\
\text { mediation }\end{array}$ & Z \\
\hline Park management & & & & \\
\hline $\begin{array}{c}\text { Tourist satisfaction } \\
\text { without mediator }\end{array}$ & 0.765 & 0.62 & & \\
\hline $\begin{array}{l}\text { Park management } \\
\text { Tourist satisfaction } \\
\text { with mediator }\end{array}$ & $\rightarrow 0.699$ & 0.081 & Partial & 3.4 \\
\hline
\end{tabular}

\section{DISCUSSION AND RECOMMENDATIONS}

This study investigated the relationship between Kinabalu park management with regard to tourism development and conservation programs on tourist satisfaction and environmental issues. Tourism and the environment have been a focal point for several studies (Ferreira \& Harmse, 2014; Nicholas et al., 2009). According to Zhong, Deng, Song, and Ding (2011), theories of environmental science and tourism have been used to assess and develop measures for sustainable environmental tourism. For Kinabalu Park, the investigation of the relationship between park management, environmental issues, and tourist satisfaction is 
PLANNING MALAYSIA

Journal of the Malaysia Institute of Planners (2020

important for future planning, management, and the implementation of tourism programs or activities. As a world class recognized biodiversity hotspots, this assessment is necessary to: (a) measure tourist satisfaction, and (b) understand the experience and opinion of tourists with respect to the management of the park and environmental issues.

Tables 3 and 4 present an overview of the results of hypothesis testing. Based on 351 responses, this analysis confirms the relationships described in each of the research hypotheses. The first and second hypotheses describe the effects of park management on tourist satisfaction and environmental issues. The results show that park management has a substantial and positive influence on environmental issues and tourist satisfaction. Visitors indicated a belief that effective park management was important for environmental and tourist satisfaction. Tourists specifically emphasized the importance of having effective park management strategies related to environmental issues. Participants agreed that each of the proposed park management strategies played an important role in conserving the ecosystem and increasing tourist satisfaction. These park management strategies include the implementation of a carrying capacity policy and establishing standards for development, establishing conflict resolution strategies and zoning for multiple uses, increasing knowledge and awareness through education and communication campaigns, broader management of tourist activities, and more effective enforcement of park rules and regulations.

Destination or park management has been an important topic in discussions pertaining to rural tourism since the early 2000s. As an ecotourism and UNESCO world heritage site, Kinabalu National Park is obligated to conserve its environment, including flora, fauna, and human culture. Therefore, efforts to improve the efficacy of Kinabalu's park management will have practical benefits for tourism (Benedetto et al., 2016). Effective tourism management coupled with appropriate planning can help to ensure that the park's tourism resources remain sustainable. Moreover, effective tourism management is a collaborative strategy inclusive of formulation, planning, implementation, and evaluation. Therefore, an integrated planning and management approach is necessary to achieve tourist satisfaction and sustainable tourism development (Nicholas et al., 2009). Previous research has shown that the effective management of national parks plays a vital role in ensuring the park's sustainability (Ferreira \& Harmse, 2014). Getzner et al. (2014) observe that, in most cases, effective park management is function of policy development and implementation. Therefore, it is necessary to develop appropriate environmental tourism policies, laws and regulations to promote environmental conservation (Benedetto et al., 2016). To this end, in terms of the future development of Kinabalu National Park, tourism management practices should emphasis tourist satisfaction and environmental conservation. 
Normah Abdul Latip \& Mastura Jaafar, Azizan Marzuki, K.M. Roufechaei, MU Umar

Spectacle of Conservation and Tourism in Protected Areas: Analysis of Management, Issues and Tourist Satisfaction

In addition, controlling and managing the potentially environmentally destructive activities of tourists is important in order to promote conservation and the preservation of the natural environment. Emphasizing the implementation of appropriate national tourism policies and legislation can help to improve the conservation and sustainable development of Kinabalu Park. Moreover, successful ecotourism development and tourist satisfaction is contingent upon ensuring that these policies and laws are sufficiently robust and focused on the needs of key stakeholders involved in the tourism planning process (Bulatovic \& Tripkovic-Markovic, 2015).

Testing the third hypothesis (re: the effects of environmental issues on tourist satisfaction) showed a positive result. The development of ecotourism and promotion of environmental issues plays an important role in improving tourist satisfaction in Kinabalu National Park. The literature would suggest that ecotourism and environmental issues exert a positive effect on tourist satisfaction (Benedetto et al., 2016; Xu \& Fox, 2014).

Testing the fourth hypothesis involved analyzing the indirect effects of park management and tourist satisfaction, using environmental issues as a mediating role. This fourth hypothesis was partly supported. This result indicates that the management of Kinabalu National Park needs to take a more active role in every aspect of the park's environmental conservation and ecotourism development if it is to actively promote tourist satisfaction. Wilderness destinations with better park management and planning strategies tend to be much more effective in attracting international tourism (Getzner et al., 2014). Therefore, a renewed focus on environmental issues and ecotourism development in Kinabalu National Park should result in improved tourist satisfaction. This idea is consistent with argument extended by Inglis et al. (2005), that park management strategies should be designed to fulfil multiple objectives in terms of attracting new visitors and new residents, while simultaneously promoting conservation, thus supporting sustainable tourism development.

The findings presented in this paper detail the relationship between park management, environmental issues, and tourist satisfaction in Kinabalu National Park. The result indicate that Sabah Parks should focus on park management as a key factor in the planning and implementation of tourism programs in relation to Kinabalu National Park. The interaction between park management, tourist satisfaction, and environment or sustainability provides an opportunity to identify to new strategies for the development of Kinabalu National Park.

As the number of visitors to Kinabalu National Park continues to rise, Sabah Parks has an obligation to strengthen its policies in relation to the environment. Our findings indicated that attention to environmental issues is as an essential component of an integrated approach to overall park management and to the promotion of tourist satisfaction. Particularly attention should be paid to tourism development planning and park management strategies, ensuring that 
PLANNING MALAYSIA

Journal of the Malaysia Institute of Planners (2020

these strategies are intrinsically linked to the protection and conservation of the park's ecosystems. This integrated approach to the management of Kinabalu National Park ultimately aims to maximize the potential of the visitor experience, and ensure that the visitor in ideally poised to reap the maximum benefits derived from visiting the park. In turn, satisfied visitors boost the operation of the park's management, resulting in repeat tourist visitation and attracting new visitors.

Sabah Parks has at their disposal a range of strategic management models from which to choose from for the management of protected areas. These park management strategies attempt to address, and in some cases balance, ecological, community, and financial imperatives and objectives. An understanding of policies and legislation underpinning park management systems in various countries illustrates the diversity of interests and priorities of governments in addressing these challenges (Inglis et al., 2005). Consequently, it is imperative that park managers seek to understand, evaluate, and document the concerns of key stakeholders and visitors, and developing appropriate policies in response to these concerns. This framework can facilitate the process of identifying the right park management model for promoting the sustainability of Kinabalu National Park well into the future. Effective park management will inevitably require the implementation of a range of strategies aimed at controlling and managing the ecological impact of visitor activity. In addition to the selection of the correct park management model, park management must ensure the consistent monitoring and assessment of visitor impacts in order to manage and conserve ecologically sensitive areas.

The findings of this study lead us to recommend that key stakeholders be incorporated in the future planning and management of the park. Park management should be prepared to consider the implementation of new policies and practices aimed at addressing various environmental issues and tourist satisfaction. To this end, park management should look beyond traditional approaches and seek input from subject expertise in order to develop a revised strategic management model for park management. As such, visitor activities should aim to ensure a negligible environmental impact. In addition, visitors should be educated and informed as to the park's rules ahead of visiting protected areas, thus promoting the protection of the park's original integrity and value. Ideally, tourist behaviors and activities will have a positive impact on maintaining the environmental. Moreover, the park's management will have a close relationship with whatever tourism programs or activities are provided onsite. Tourism brings additional funding to the park, which the park depends upon for its facilities and resources. Therefore, every aspect of the proposed tourism program has the potential to provide significant benefits for the park. Future research should explore the issue of what tourism programs might be considered appropriate for protected areas given the need to prioritize conservation. 
Normah Abdul Latip \& Mastura Jaafar, Azizan Marzuki, K.M. Roufechaei, MU Umar

Spectacle of Conservation and Tourism in Protected Areas: Analysis of Management, Issues and Tourist Satisfaction

\section{ACKNOWLEDGEMENTS}

The authors would like to acknowledge Universiti Sains Malaysia for providing the Research University Grants (RU), Grant No: 1001/PPBGN/8016051 as financial support to conduct this research.

\section{REFERENCES}

Abdul Latip, N., Badarulzaman, N., Marzuki, A., \& Umar, M. U. (2013). Sustainable Forest Management in Lower Kinabatangan, Sabah: Issues and Current Practices. PLANNING MALAYSIA JOURNAL, 11(3), 59-84. http://dx.doi.org/10.21837/pmjournal.v11.i3.108

Andrea, V., Tampakis, S., Tsantopoulos, G., \& Manolas, E. (2014). Environmental problems in protected areas: Stakeholders' views with regard to two neighboring national parks in Greece. Management of Environmental Quality: An International Journal, 25(6), 723-737. https://doi.org/10.1108/MEQ-01-20140006

Azam, M., Mahmudul Alam, M., \& Haroon Hafeez, M. (2018). Effect of tourism on environmental pollution: Further evidence from Malaysia, Singapore and Thailand. Journal of Cleaner Production, 190, 330-338. https://doi.org/10.1016/j.jclepro.2018.04.168

Bajs, I. P. (2015). Tourist perceived value, relationship to satisfaction, and behavioral intentions: the example of the Croatian tourist destination Dubrovnik. Journal of Travel Research, 54(1), 122-134. https://doi.org/10.1177/0047287513513158

Baker, D. A., \& Crompton, J. L. (2000). Quality, satisfaction and behavioral intentions. Annals of Tourism Research, 27(3), 785-804. https://doi.org/10.1016/S01607383(99)00108-5

Banyai, M. (2012). Assessing visitors' satisfaction at parks Canada sites (Doctoral thesis, University of Waterloo). Retrieved from https://www.collectionscanada.gc.ca/obj/thesescanada/vol2/OWTU/TC-OWTU6711.pdf

Benedetto, G., Carboni, D., \& Corinto, G. L. (2016). Governance of sustainable tourism in a vast area surrounding a national park. Procedia Environmental Sciences, 32, 38-48. https://doi.org/10.1016/j.proenv.2016.03.010

Bennett, N. J., \& Dearden, P. (2014). Why local people do not support conservation: Community perceptions of marine protected area livelihood impacts, governance and management in Thailand. Marine policy, 44, 107-116.

Blanke, J., \& Chiesa, T. (Eds.). (2013). The Travel and Tourism Competitiveness Report 2013. Retrieved from http://www3.weforum.org/docs/WEF_TT_Competitiveness_Report_2013.pdf

Buckley, R., Robinson, J., Carmody, J., \& King, N. (2008). Monitoring for management of conservation and recreation in Australian protected areas. Biodiversity and Conservation, 17(14), 3589-3606. https://doi.org/10.1007/s10531-008-9448-7

Bulatovic, I., \& Tripkovic-Markovic, A. (2015). Strategic management of tourism in the national parks: Case: National Park Skadar Lake. Turizam, 19(3), 127-138. https://doi.org/10.5937/Turizam1503127B 
Chin, W. W. (2010). How to write up and report PLS analyses. In V. Esposito Vinzi, W. W. Chin, J. Henseler, \& H. Wang (Eds.), Handbook of Partial Least Squares (pp. 655-690). https://doi.org/10.1007/978-3-540-32827-8_29

Connell, J., Page, S. J., \& Bentley, T. (2009). Towards sustainable tourism planning in New Zealand: Monitoring local government planning under the Resource Management Act. Tourism Management, 30(6), 867-877. https://doi.org/10.1016/j.tourman.2008.12.001

Correia, A., Kozak, M., \& Ferradeira, J. (2013). From tourist motivations to tourist satisfaction. International Journal of Culture, Tourism and Hospitality Research, 7(4), 411-424. https://doi.org/10.1108/IJCTHR-05-2012-0022

Dudley, N. (Ed.). (2008). Guidelines to Applying Protected Area Management Categories. Retrieved

from https://portals.iucn.org/library/sites/library/files/documents/PAG-021.pdf

Eagles, P. F. J. (2002). Trends in park tourism: economics, finance and management. Journal of Sustainable Tourism, 10(2), 132-153.

Eagles, P. F. J. (2014). Research priorities in park tourism. Journal of Sustainable Tourism, 22(4), 528-549. https://doi.org/10.1080/09669582.2013.785554

Fennell, D., \& Nowaczek, A. (2010). Moral and empirical dimensions of human-animal interactions in ecotourism: Deepening an otherwise shallow pool of debate. Journal of Ecotourism, 9(3), 239-255.

https://doi.org/10.1080/14724041003741519

Ferreira, S., \& Harmse, A. (2014). Kruger National Park: Tourism development and issues around the management of large numbers of tourists. Journal of Ecotourism, 13(1), 16-34. https://doi.org/10.1080/14724049.2014.925907

Getzner, M., Vik, M. L., Brendehaug, E., \& Lane, B. (2014). Governance and management strategies in national parks: Implications for sustainable regional development. International Journal of Sustainable Society, 6(1/2), 82. https://doi.org/10.1504/IJSSOC.2014.057891

Gilmore, A., \& Simmons, G. (2007). Integrating sustainable tourism and marketing management: Can National Parks provide the framework for strategic change? Strategic Change, 16(5), 191-200. https://doi.org/10.1002/jsc.798

Götz, O., Liehr-Gobbers, K., \& Krafft, M. (2010). Evaluation of Structural Equation Models Using the Partial Least Squares (PLS) Approach. In V. Esposito Vinzi, W. W. Chin, J. Henseler, \& H. Wang (Eds.), Handbook of Partial Least Squares (pp. 691-711). https://doi.org/10.1007/978-3-540-32827-8_30

Hair, J. F., Ringle, C. M., \& Sarstedt, M. (2011). PLS-SEM: Indeed a Silver Bullet. Journal of Marketing Theory and Practice, 19(2), 139-152. https://doi.org/10.2753/MTP1069-6679190202

Henderson, A., \& Fry, C. R. (2011). Better parks through law and policy: a legal analysis of authorities governing public parks and open spaces. Journal of Physical Activity and Health, 8(s1), S109-S115. https://doi.org/10.1123/jpah.8.s1.s109

Henseler, J., Ringle, C. M., \& Sinkovics, R. R. (2009). The use of partial least squares path modeling in international marketing. In R. R. Sinkovics \& P. N. Ghauri (Eds.), Advances in International Marketing (Vol. 20, pp. 277-319). https://doi.org/10.1108/S1474-7979(2009)0000020014 
Normah Abdul Latip \& Mastura Jaafar, Azizan Marzuki, K.M. Roufechaei, MU Umar

Spectacle of Conservation and Tourism in Protected Areas: Analysis of Management, Issues and Tourist Satisfaction

Huang, Y., Deng, J., Li, J., \& Zhong, Y. (2008). Visitors' attitudes towards China's national forest park policy, roles and functions, and appropriate use. Journal of Sustainable Tourism, 16(1), 63-84. https://doi.org/10.2167/jost720.0

Inglis, J., Pearlman, M., \& Whitelaw, P. (2005). Best practice in strategic park management: Towards an integrated park management mode. Gold Coast, Australia: CRC for Sustainable Tourism.

Jaafar, M., Kayat, K., Tangit, T. M., \& Yacob, M. F. (2013). Nature-based rural tourism and its economic benefits: A case study of Kinabalu National Park. Worldwide Hospitality and Tourism Themes, 5(4), 342-352. https://doi.org/10.1108/WHATT-03-2013-0016

Jenkins, J., \& Pigram, J. (2003). Outdoor recreation. In J. Jenkins \& J. Pigram (Eds.), Encyclopedia of Leisure and Outdoor Recreation. London, England: Routledge.

Jimura, T. (2011). The impact of world heritage site designation on local communities A case study of Ogimachi, Shirakawa-mura, Japan. Tourism Management, 32(2), 288-296. https://doi.org/10.1016/j.tourman.2010.02.005

Johnston, R. J., \& Tyrrell, T. J. (2007). Management exercises and trainer's note in sustainable tourism and dynamics. International Journal of Culture, Tourism and Hospitality Research, 1(4), 328-337. https://doi.org/10.1108/17506180710824217

Landorf, C. (2009). Managing for sustainable tourism: A review of six cultural World Heritage Sites. Journal of Sustainable Tourism, 17(1), 53-70. https://doi.org/10.1080/09669580802159719

Latip, N. A., Marzuki, A., Ahmad, A. G., Umar, M. U., \& Rais, N. S. (2015). Ecological carrying capacity in the conservation of Mount Kinabalu: A Theoretical and Conceptual Framework. Australian Journal of Basic and Applied Sciences, 9(7), 354-357. http://www.ajbasweb.com/old/ajbas/2015/April/354-357.pdf

Latip, N. A., Rasoolimanesh, S. M., Jaafar, M., Marzuki, A., \& Umar, M. U. (2018). Indigenous residents' perceptions towards tourism development: a case of Sabah, Malaysia. Journal of Place Management and Development. https://doi.org/10.1108/JPMD-09-2017-0086

Lee, C.-F. (2015). Tourist satisfaction with factory tour experience. International Journal of Culture, Tourism and Hospitality Research, 9(3), 261-277. https://doi.org/10.1108/IJCTHR-02-2015-0005

Lillestol, T., Timothy, D. J., \& Goodman, R. (2015). Competitive strategies in the US theme park industry: A popular media perspective. International Journal of Culture, Tourism and Hospitality Research, 9(3), 225-240. https://doi.org/10.1108/IJCTHR-02-2015-0009

Nicholas, L. N., Thapa, B., \& Ko, Y. J. (2009). Residents' perspectives of a world heritage site. Annals of Tourism Research, 36(3), 390-412. https://doi.org/10.1016/j.annals.2009.03.005

Preacher, K. J., \& Hayes, A. F. (2008). Asymptotic and resampling strategies for assessing and comparing indirect effects in multiple mediator models. Behavior Research Methods, 40(3), 879-891. https://doi.org/10.3758/BRM.40.3.879

Qian, C., Sasaki, N., Shivakoti, G., \& Zhang, Y. (2016). Effective governance in tourism development - An analysis of local perception in the Huangshan mountain area. 
PLANNING MALAYSIA

Journal of the Malaysia Institute of Planners (2020

Tourism Management Perspectives, 20, 112-123. https://doi.org/10.1016/j.tmp.2016.08.003

Rabbany, Md. G., Afrin, S., Rahman, A., Islam, F., \& Hoque, F. (2013). Environmental effects of tourism. American Journal of Environment, Energy and Power Research, 1(7), 117-130.

Rasoolimanesh, S. M., Dahalan, N., \& Jaafar, M. (2016). Tourists' perceived value and satisfaction in a community-based homestay in the Lenggong Valley World Heritage Site. Journal of Hospitality and Tourism Management, 26, 72-81. https://doi.org/10.1016/j.jhtm.2016.01.005

Reinartz, W., Haenlein, M., \& Henseler, J. (2009). An empirical comparison of the efficacy of covariance-based and variance-based SEM. International Journal of Research in $\quad$ Marketing, 26(4), 332-344. https://doi.org/10.1016/j.ijresmar.2009.08.001

Robaina-Alves, M., Moutinho, V., \& Costa, R. (2016). Change in energy-related CO2 (carbon dioxide) emissions in Portuguese tourism: A decomposition analysis from 2000 to 2008. Journal of Cleaner Production, 111, 520-528. https://doi.org/10.1016/j.jclepro.2015.03.023

Sangpikul, A. (2018). The effects of travel experience dimensions on tourist satisfaction and destination loyalty: The case of an island destination. International Journal of Culture, Tourism and Hospitality Research, 12(1), 106-123. https://doi.org/10.1108/IJCTHR-06-2017-0067

Shahbaz, M., Solarin, S. A., Sbia, R., \& Bibi, S. (2015). Does energy intensity contribute to $\mathrm{CO} 2$ emissions? A trivariate analysis in selected African countries. Ecological Indicators, 50, 215-224. https://doi.org/10.1016/j.ecolind.2014.11.007

Sobel, M. E. (1982). Asymptotic confidence intervals for indirect effects in structural equation models. Sociological Methodology, 13, 290-312. https://doi.org/10.2307/270723

Tabachnick, B. G., \& Fidell, L. S. (2007). Using multivariate statistics (5th ed.). Boston, MA: Pearson.

Tay, K. X., Chan, J. K. L., Vogt, C. A., \& Mohamed, B. (2016). Comprehending the responsible tourism practices through principles of sustainability: A case of Kinabalu Park. Tourism Management Perspectives, 18, 34-41. https://doi.org/10.1016/j.tmp.2015.12.018

Tayet, P., Agamez, P. \& Chaskel, R. (2016). Trastornos de ansiedad en lainfancia y la adolescencia. Curso continuo de actualización en pediatria CCAP. 15(1). 6-18. Recuperado de https://scp.com.co/wp-content/uploads/2016/04/1.Trastornosansiedad-1.pdf

Thomas, L., \& Middleton, J. (2008). Guidelines for Management Planning of Protected Areas. International Union for Conservation of Nature: Gland, Switzerland.

Tubb, K. N. (2003). An evaluation of the effectiveness of interpretation within Dartmoor National Park in reaching the goals of sustainable tourism development. Journal of Sustainable Tourism, 11(6), 476-498. https://doi.org/10.1080/09669580308667217

Weaver, D. (2000). Tourism and national parks in ecologically vulnerable areas. In R. Butler \& S. W. Boyd (Eds.), Tourism and National Parks: Issues and Implications (pp. 107-124). Chichester, England: John Wiley \& Sons. 
Normah Abdul Latip \& Mastura Jaafar, Azizan Marzuki, K.M. Roufechaei, MU Umar

Spectacle of Conservation and Tourism in Protected Areas: Analysis of Management, Issues and Tourist Satisfaction

World Tourism Organization. (1992). Development of National Parks and Protected Areas for Tourism. Madrid, Spain: World Tourism Organization.

$\mathrm{Xu}, \mathrm{F}$., \& Fox, D. (2014). Modelling attitudes to nature, tourism and sustainable development in national parks: A survey of visitors in China and the UK. Tourism Management, 45, 142-158.

https://doi.org/10.1016/j.tourman.2014.03.005

Yousuf, T., \& Ali, M. (2018). Tourist satisfaction, environmental concerns and tourism in and beyond Dal Lake, Kashmir. Journal of Tourism \& Hospitality, 07(02). https://doi.org/10.4172/2167-0269.1000349

Zhong, L., Deng, J., Song, Z., \& Ding, P. (2011). Research on environmental impacts of tourism in China: Progress and prospect. Journal of Environmental Management, 92(11), 2972-2983. https://doi.org/10.1016/j.jenvman.2011.07.011

Received: $15^{\text {th }}$ May 2020. Accepted: $1^{\text {st }}$ Sept 2020 